\title{
Uso da literatura fantástica no ensino de história da química: Harry Potter e a pedra filosofal
}

Use of fantastic literature in the teaching of the history of chemistry: Harry Potter and the philosopher's stone

Uso de la literatura fantástica en la enseñanza de la historia de la química: Harry Potter y la piedra filosofal

Murilo Rodrigues dos Santos ORCID: https://orcid.org/0000-0002-8181-6460 Instituto Federal de Educação, Ciência e Tecnologia do Ceará, Brasil E-mail: murilo.rodrigues.c.n@gmail.com

Francisca Helena de Oliveira Holanda ORCID: https://orcid.org/0000-0001-5555-5394 Instituto Federal de Educação, Ciência e Tecnologia do Ceará, Brasil E-mail: hramcysca@yahoo.com.br

Maria Cleide da Silva Barroso

ORCID: https://orcid.org/0000-0001-5577-9523 Instituto Federal de Educação, Ciência e Tecnologia do Ceará, Brasil E-mail: ccleideifcemaraca@gmail.com

Caroline de Goes Sampaio

ORCID: https://orcid.org/0000-0002-3642-234X Instituto Federal de Educação, Ciência e Tecnologia do Ceará, Brasil E-mail: carol-quimica@ hotmail.com

\begin{abstract}
Resumo
O presente artigo tem como seu objetivo principal trazer os livros paradidáticos/de literatura como ferramenta pedagógica a ser utilizada pelos professores de Química no Ensino Médio, a fim de ajudar os docentes a aumentar sua bagagem pedagógica, facilitando a forma de transmitir conteúdos e evidenciando a seus discentes como ocorrem as descobertas científicas, os fatos e mitos presentes nos livros de fantasia, utilizando como exemplo a pseudociência que foi a alquimia. Foi realizado uma profunda pesquisa de cunho qualitativa acerca de livros, cuja principal temática se relacionasse a fantasia e com utilidade no ensino. A escolha no horizonte do mágico, do fantástico, da fantasia, deu-se devido a um aumento da capacidade imaginativa provocada quando se lê obras desse cunho, e devido a facilidade linguística com que os alunos do ensino médio estão familiarizados, uma linguagem que os aproxime da leitura e os deixem emergidos no mundo da imaginação e da criatividade. No final do artigo podemos evidenciar a pouca utilização de livros paradidáticos/de literatura em áreas diversificadas do ensino.
\end{abstract}

Palavras-chave: Livros paradidáticos; Ferramenta pedagógica; Ensino; Química; Alquimia.

\begin{abstract}
The main objective of this article is to bring paradidactic / literature books as a pedagogical tool to be used by Chemistry teachers in high school, in order to help teachers increase their pedagogical background, facilitating the way of transmitting content and highlighting the its students how scientific discoveries, facts and myths occur in fantasy books, using as an example the pseudoscience that was alchemy. In-depth qualitative research was carried out on books, whose main theme was related to fantasy and useful in teaching. The choice on the horizon of the magician, the fantastic, the fantasy, was due to an increase in the imaginative capacity provoked when reading works of this nature, and due to the linguistic ease with which high school students are familiar, a language that approach reading and let them emerge in the world of imagination and creativity. At the end of the article, we can highlight the little use of paradidactic books / literature in diverse areas of teaching.
\end{abstract}

Keywords: Paradidactic books; Pedagogical tool; Teaching; Chemistry; Alchemy.

\section{Resumen}

El objetivo principal de este artículo es acercar los libros paradidácticos / literarios como una herramienta pedagógica para ser utilizada por los profesores de Química en el bachillerato, con el fin de ayudar a los docentes a incrementar su formación pedagógica, facilitando la forma de transmitir contenidos y resaltando a sus estudiantes la forma científica. Los descubrimientos, hechos y mitos ocurren en los libros de fantasía, tomando como ejemplo la pseudociencia que fue la alquimia. Se realizó una investigación cualitativa en profundidad sobre libros, cuyo tema principal estaba 
relacionado con la fantasía y era útil en la docencia. La elección en el horizonte del mago, lo fantástico, la fantasía, se debió a un aumento de la capacidad imaginativa que se provoca al leer obras de esta naturaleza, y a la facilidad lingüística con la que están familiarizados los estudiantes de secundaria, un lenguaje que se acerca leer y dejarlos emerger en el mundo de la imaginación y la creatividad. Al final del artículo, podemos destacar el escaso uso de libros / literatura paradidáctica en diversas áreas de la docencia.

Palabras clave: Libros paradidácticos; Herramienta pedagógica; Ensenãnza; Química; Alquimia.

\section{Introdução}

A química está, indubitavelmente, presente no cotidiano de todos, por isso torna-se uma ciência fundamental para a compreensão do mundo que nos cerca. Entretanto, muitas vezes o único aspecto que é levado em consideração no estudo desta ciência são a memorização de fórmulas, sejam matemáticas ou químicas, decoração de conceitos e isso muito contribui para que seja uma área a ser rejeitada pelos alunos. Outro ponto que desfavorece o entusiasmo no estudo da química é sua abstração, haja vista que para alguns conceitos seria mais adequado o uso da experimentação ao invés de conteúdos passados verbalmente, o que exige muito da capacidade imaginativa de cada aluno.

Cabe a figura do professor tornar os conteúdos, mesmo aqueles mais abstratos, o mais atrativo o possível, explicar ao aluno que o estudo desta ciência faz com que o homem, enquanto ser pensante, possa enxergar o mundo ao seu redor de forma muito mais ampla, tendo o poder de criticar e interagir com o meio. Podendo ainda atuar mutuamente solucionando problemas com conceitos que foram estudados nessa área da ciência (química). Com isso aulas que são baseadas em conceitos de memorização podem ser substituídas por aulas que vinculem o conhecimento e sua aplicabilidade. Para que isso ocorra é importante também que o aluno entenda de onde vem o conhecimento que está estudando.

Os aspectos históricos das descobertas cientificas é de suma importância para o aprendizado de conteúdos abordados em sala de aula; visam o comportamento histórico da sociedade em que se deu a descoberta, o aspecto humano da conquista, afinal de contas é por mãos humanas que se dão as descobertas, e através de observações macroscópicas são formuladas leis e teorias.

Logo se evidencia a importância desses aspectos, pois é importante que os alunos saibam que a ciência não é algo inerte, mas uma verdadeira locomotiva em movimento em que diariamente conceitos são derrubados e novas ideias são propostas para contrapor formulações feitas anteriormente.

Com isso podemos destacar a importância da leitura como uma ferramenta pedagógica demasiadamente importante. Não apenas a leitura de textos técnicos, com linguagem difícil, mas a leitura de livros paradidáticos e históricos que funcionem como escape e como material de apoio nos conteúdos abordados pelo professor em sala de aula. Com isso, o trabalho do professor se torna mais valorizado, pois ele buscará sanar as dúvidas advindas de outras fontes de leitura, incitando a curiosidade e a imaginação, aspectos muito importantes no processo de aprendizagem.

Livros paradidáticos são pouco utilizados no aspecto educacional como uma ferramenta didática de ensino. Uma das áreas que podemos destacar que faz uso desta ferramenta é a Literatura, componente curricular das escolas de ensino fundamental e ensino médio. Os livros paradidáticos são utilizados nesta disciplina para que os alunos possam evidenciar as mudanças socioculturais que a Língua Portuguesa passou no decorrer dos anos, bem como conhecer os autores de seu país e obras clássicas, além de estimular o hábito da leitura e interpretação de texto, fazendo com que os alunos possam escrever textos de cunho avaliativo sobre a obra que leram; logo, podemos citar alguns autores de peso cuja nacionalidade é brasileira: Machado de Assis, Monteiro Lobato, Jorge Amado. 


\section{Metodologia}

Esta pesquisa foi realizada a partir de um estudo teórico na qual foi realizado um pesquisa documental de cunho qualitativo onde aspectos socioculturais foram levados em consideração. Segundo Rhoden e Zancan (2020):

Nas ciências humanas e sociais, em que se situa a ciência da educação, a pesquisa qualitativa ocupa lugar de destaque, pois assegura uma abordagem na qual a compreensão e a interpretação são mais importantes do que a descrição ou a explicação de um fenômeno. Isso significa que, na pesquisa em educação, interessa mais desvendar os significados profundos do observado do que os imediatamente aparentes. Rhoden e Zancan (2020).

As principais pesquisas feitas para a realização deste artigo foram textos publicados entre os anos de 1987 a 2006 haja vista que as literaturas encontradas atualmente não contemplam o uso de um livro todo como ferramenta pedagógica e só abrangem as adaptações feita inspiradas nas obras literárias, fazendo um estudo de caso sobre a importância da literatura no ensino médio e a importância da História da Ciência na formação social de alunos; o levantamento bibliográfico foi realizado a partir de livros de literatura fantástica, como os livros de Harry Potter, e livros sobre educação e as dificuldades encontradas por alunos nas mais diversas áreas estudadas.

As leituras tiveram de ter o mais alto grau de criticidade, pois boa parte dos textos que abordam literatura como ferramenta pedagógica dão mais importância as atividades realizadas fora do ambiente da sala de aula, e não vislumbram o potencial que podem ter quando exploradas na forma de uma boa leitura. Além de utilizar apenas poucos trechos do livro e após abandonam a obra.

Um ponto que vale a pena ser mencionado é que algumas literaturas se atêm apenas as adaptações cinematográficas realizada sobre as obras escritas, o que faz com que se perca uma percepção própria da temática da obra, além do distanciamento da originalidade já que as adaptações cinematográficas são na visão do diretor.

\section{O Uso da Literatura Fantástica como Ferramenta Didática}

A disciplina de Literatura comumente aborda, no Ensino Médio, textos, artigos e livros cujo caráter disciplinar vai além do caráter acadêmico, tornado o aluno sensível e criando o hábito de leitura. Estes livros/textos/artigos são, muitas vezes, sobre determinada época histórica, autores de tempos literários divergentes, para que o aluno se sinta instigado a buscar saber mais sobre a Língua Portuguesa, para que entenda as mudanças e transformações que ocorreram na Língua durante o período a ser estudado, o estilo de escrita de cada autor, as motivações que o levaram a escrever, as críticas sociais, muitas vezes escondidas nas entrelinhas de seus textos, que dão um toque pessoal de cada autor.

Porém, um fator que vale a pena destacar é a utilização de livros paradidáticos apenas em disciplinas que abrangem a grande área de Linguagens e Códigos, tendo uma verdadeira carência em outras áreas, bem como Matemática e suas Tecnologias e Ciências da Natureza.

Notoriamente, um dos grandes influenciadores para o desinteresse que os estudantes sentem com relação a leitura talvez seja a falta de motivação ao hábito de ler. Entretanto, também vale a pena destacar que outro grande influenciador seja a falta de literatura que seja do gosto pessoal do aluno, leituras cativantes sempre inspiram a criatividade e a imaginação do ser humano, haja visto que na história da humanidade, do ser humano é motivada através de várias formas de expressão, sendo a literatura uma delas. De acordo com Smolka (2009):

É na trama social, com base no trabalho e nas ideias dos outros, nomeados ou anônimos, que se pode criar e produzir o novo. Não se cria do nada. A particularidade da criação no âmbito individual implica, sempre, um modo de apropriação e participação na cultura e na história. (Smolka, 2009, p.10). 
A tendência de se utilizar literatura paradidática em outras áreas da Educação como Ciências, por exemplo, pode vir a ser uma importante ferramenta facilitadora no aprendizado do aluno, facilitadora no trabalho do professor, influenciadora no aspecto social da vida do aluno.

Existem vários livros que podem ser citados como ferramenta pedagógica a ser utilizada por professores; como O Diabo dos Números (1997) do poeta alemão Hans Magnus Enzensberger, que desmitifica a matemática como sendo algo a ser temido por tudo e por todos, em que apenas gênios brilhantes conseguem entendê-la; no livro o aluno consegue acompanhar a estória de Robert, o menino do pijama azul e Teplotaxl, um diabo que se utiliza dos números para encantar o garoto, este livro seria uma ótima dica aos professores de Matemática que sentem dificuldade em passar conhecimento a seus alunos, que, por motivos quaisquer, podem ter enraizado no subconsciente que não conseguirão aprender matemática nunca. Outro livro que pode ser utilizado por professores, desta vez de biologia, é o fantástico Vinte Mil Léguas Submarinas (2014) do escritor francês Jules Verne, que em suas páginas aborda temas como animais elétricos, poluição dos oceanos por meio da Revolução Industrial, além de descrever em detalhes a fauna e a flora marinha. Fundação (2019) do escritor e cientista bioquímico Isaac Asimov aborda temas sociopolíticos em uma trama de ficção científica, o que seria perfeito para ser utilizado em aulas interdisciplinares entre as disciplinas de história e ciências no geral.

Como podemos perceber, a literatura paradidática é uma importante ferramenta pedagógica que auxilia o professor em contextualizar abordagens em sala de aula com seus alunos, tomando exemplos fantasiosos com o foco de instigar conhecimento, criatividade, distinção entre realidade e o sonho. Os autores usam de imaginação inventando algum termo, ou até mesmo usando conceitos existentes com outros nomes, de criação própria. Pois, ao utilizar esses exemplos o professor também poderá ajudar seu aluno a desenvolver algo muito importante para o aprendizado de seu discente: a Imaginação. Uma importante ferramenta pedagógica pouco explorada.

\section{Imaginação como Aliada no Aprendizado}

Com a utilização de livros paradidáticos com a função de auxiliar o professor em seu importante trabalho, também se está exercitando a imaginação do aluno. Ora, se todos os alunos lerem o mesmo livro, ao mesmo tempo, todos terão diferentes concepções. Sejam concepções da ambientação descrita no livro, a descrição dos personagens, a própria concepção política que possa envolver o enredo torna-se única para cada um.

Com a leitura, estimulamos muito a imaginação do aluno, não tanto quanto se estimularia em uma aula de campo ou uma "aula peripatética" seguindo a ideia de Aristóteles (384 a.C - 322 a.C) que era, além de filósofo, um grande professor que ensinava enquanto caminhava ao ar livre ou sob as árvores. Nesses exemplos de aulas o aluno está muito mais imergido, logo ele se encontra em um local talvez nunca visitado, porém neste tipo de aula a desconcentração torna-se muito mais frequente, haja vista a facilidade de a imaginação fluir em locais novos. Já com a leitura a imaginação torna-se refém do texto a ser lido.

Algo que vale a pena destacar é a interferência histórico-social na imaginação, pois, para Vygotsky (1996) a história é o fundamento do entendimento científico do psiquismo. Portanto, compreender a imaginação é compreender como esse conceito foi pouco a pouco ganhando forma e pôde produzir o desenvolvimento do pensamento humano nas relações históricas da sociedade. Desta forma, um povo considerado primitivo jamais poderia definir esse conceito em seu sentido real, já que esta definição só ocorre perante uma cultura complexa, que serve de ferramenta para entendimento mais íntimo das relações humanas e seus sentimentos.

Os filósofos do período histórico conhecido como Iluminismo (séc. XVII e XVIII) já tentavam buscar um significado plausível para a imaginação e desde então a imagem, compreendida como uma forma de sentido cerebral, foi atribuída a esta característica humana. Ora, a utilização da imaginação é algo proveniente de uma imagem, mas que vai além disso e ganha consciência própria, Sartre (1996) reverencia este conceito em suas obras. 
O conceito de imaginação proveniente de imagem também foi utilizado pelo filósofo e matemático René Descartes (1984), Descartes foi um dos primeiros a utilizar o conceito de imaginação quando discorre sobre as paixões da alma e quando equipara com as paixões ocasionadas pelo corpo diz que na primeira há uma interferência da imaginação, enquanto na segunda é apenas um impulso causado pelos nervos.

Platão (428 a.C - 348 a.C) em seu debate sobre o antagonismo entre alma e sentido mantém a dicotomia entre o "dentro" e o "fora", na qual o "fora" é o mundo material e o "dentro" um mundo interior, na qual podemos supor que o filósofo se referia ao ato de imaginar. Vygotsky (2001b) vai afirmar que o "dentro" e o fora", em relação a psique humana são um só. Ora, o psiquismo é produzido na atividade humana em relação ao meio no qual o indivíduo se insere, a unidade está associada também ao "fazer" e "apropriar" da cultura histórica. Vygotsky tece críticas no âmbito do mundo das ideias que subestima a face social, histórica e cultural:

Admitindo assim, a existência de fenômenos imateriais, desprovidos de espaço, essa psicologia mantinha na íntegra a visão dualista da natureza humana própria do pensamento primitivo e religioso. Não é por acaso que essa psicologia estava estritamente ligada à filosofia idealista, que ensinava que o espírito é um princípio específico e diferente da matéria, enquanto a consciência tem uma realidade especial, autônoma, independente do ser. (VYGOTSKY, 2001a, p. 4).

Podemos então perceber que a imaginação não está separada do pensamento racional do ser humano, pois as imagens contidas na psique do aluno servem como um ícone de sustentação que dá apoio ao pensamento lógico. Por exemplo, se um aluno está estudando as transformações da matéria (assunto muito recorrente em química) e vê que é possível, através do nucleossíntese (captura ou decaimento de partículas elementares) de elementos químicos, transformar um átomo em outro, pode lhe vir a mente a imagem de alquimistas tentado transformar metais em ouro. Por esse motivo, a história da ciência é tão importante, devido a curiosidade, a realidade social e cultural, a necessidade de se expressar que cada aluno possui.

Daí a importância de as escolas possuírem laboratório de ciências, para que os alunos formem uma opinião coerente entre a imaginação e a realidade, que os permita, também, manter uma imagem consolidada por mais tempo no imaginário do aluno.

Entretanto, como afirma Barbosa (1998) somente as elites são possuidoras de códigos eruditos que são negados a grande parte da população, isto é a realidade nas escolas de ensino público, pois muitas não possuem equipamentos laboratoriais para a realização de aulas experimentais, ou mesmo não possuem um laboratório, o que torna a experiência de uma aula experimental um desejo distante na mente do aluno.

Quando um aluno o escreve ou lê irá referenciar dois aspectos: sua identidade anterior, que só é expressa por meio de uma necessidade; o outro aspecto é orientado pelas referências imaginativas e poéticas advindas das aulas e da proximidade com o professor. O primeiro é muito importante pois o aluno se verá na obra, comunicando seus aspectos imaginativos socialmente, o segundo serve para sua segurança emocional, pois ele criará algo da qual sinta orgulho. A interação entre esses dois aspectos significa que o aluno criou um código de linguagem que lhe é permitido expressar sua imaginação e sentir vontade de continuar a expressar-se.

\section{Harry Potter e a Pedra Filosofal: Fantasia Aliada ao Ensino de Química}

A ciência e a literatura são áreas que quando juntas se complementam, isso se deve as mais diferenciadas formas que a leitura sobre ciência permite ser realizada, isto se justifica com o fato de a ciência estar ligada ao dia a dia, proporcionado assim uma bagagem de conhecimento sólida e não fragmentada. Segundo Farias (2006): 
As histórias são importantes porque ensinam; educam; ampliam o conhecimento; provocam reflexões pessoais e coletivas; despertam sentimentos adormecidos; comovem; propiciam momentos de ludicidade; alimentam a cognição, o espírito e a alma; transmitem valores; recriam a memória; ativam a imaginação; aliviam as dores do coração, auxiliando na transformação pessoal e na cura dos ferimentos psíquicos; mantêm viva a tradição e expandem a linguagem, enriquecendo o vocabulário. Elas permitem, ainda, extrapolar os limites da compreensão lógica sobre o mundo, rompendo, assim, com o nosso modelo de educação escolar. (Farias, 2006, p.30).

A saga de livros da fantasia Harry Potter (1997-2007) da escritora britânica J. K. Rowling é um material rico e estimulante que está presente no cotidiano de muitos alunos devido a sua presença nas bibliotecas escolares. Em sua narrativa a autora nos apresenta um mundo ficcional que instiga vários questionamentos ao mundo real. Por esse motivo torna-se um excelente recurso pedagógico de facilitação na aprendizagem dos conceitos químicos presentes na saga, estabelecendo assim uma relação lógica de maneira natural, favorecendo o processo de ensino-aprendizagem.

Nos livros da saga Harry Potter podem ser observadas várias referências a alquimia, como símbolos, figuras, além de citar um dos alquimistas mais famosos de todos os tempos, Nicolau Flamel (1330 - 1418), por outro lado os aspectos obscuros presente na alquimia também são apresentados, as manifestações ocultas. Ora, com todos esses recursos presentes, o professor pode construir bases sólidas no quesito História da Química, afim de desmitificar a narrativa ficcional presente na obra, além de proporcionar ao aluno um olhar mais amplo e crítico de como se deu a origem da Química.

Os conhecimentos sobre alquimia são apresentados no primeiro ano do Ensino Médio, quando se apresenta a origem da Química, sendo um aspecto a ser abordado pela História dessa Ciência. O Programa Nacional do Livro e Material Didático (PNLD, 2018), oferece obras na qual a seção de História da Ciência apresenta certas curiosidades e fatos sobre alguns cientistas que contribuíram de alguma forma para a formação da Química como a ciência que conhecemos hoje. Esse tipo de informação, deveras importante, podem auxiliar na compreensão do aluno de que a Ciência é fruto de interações históricas e sociais, além, é claro, de estarem sujeitas a interesses políticos, econômicos, filosóficos, éticos; sujeita a falhas também, obviamente.

A Alquimia é responsável pelos primeiros métodos laboratoriais, bem como o surgimento dos primeiros materiais. Entretanto a alquimia está muito mais próxima ao homem do que se pode imaginar, está ligada diretamente ao desenvolvimento humano. A relação do homem antigo com as substâncias e as funções em trabalhos com metais, mineração, metalurgia, trabalho de ferreiro, curandeiro, todas estas atividades eram empregadas com algum misticismo, dessa forma surge a alquimia.

Os antigos já possuíam conhecimentos em processos químicos como a preparação de tinta, extração de metais, fabricação de medicamentos. Alguns povos, como os Babilônicos, produziam perfumes. No Egito Antigo trabalhavam com ouro, prata, cobre e ferro, os antigos Fenícios trabalhavam o chumbo. Um dos processos químicos, advindo do Antigo Egito, presente na atualidade, como o embalsamento dos mortos, estava associado a arte antiga denominada Khemeia, na qual seus praticantes eram vistos como magos ou feiticeiros.

Ao longo da história da humanidade, à medida que se deram as conquistas, invasões territoriais e com a mescla de culturas os saberes alquímicos foram miscigenados. Embora não possua caráter científico, a alquimia desenvolveu importante papel na elaboração da química como ciência moderna.

As três vertentes que regeram a alquimia durante muito tempo foram: a vã tentativa de criar um elixir que curasse todos os males dando ao homem uma longa vida, o esforço de criar vida a partir do barro, os chamados homúnculos e a investida de transmutar metais em ouro; sendo a pedra filosofal, a Grande Obra dos alquimistas, o objeto que realizaria todos estes feitos.

O primeiro livro da saga de Harry Potter, intitulado a Pedra Filosofal é o livro que possui mais referências à alquimia, desde o seu título até o interior de suas páginas. Dessa forma, pode-se apresentar ao aluno trechos do livro de forma 
que contextualize e enriqueça ainda mais o conteúdo didático que é esta obra literária; construindo assim um conhecimento não fragmentado e rico.

Em a Pedra Filosofal há uma citação de que o diretor de Hogwarts, a escola de Magia e Bruxaria da Europa que recebe jovens bruxos para aprenderem as artes mágicas, é descrito por desenvolver trabalhos em alquimia A Informação está presente nos Sapos de Chocolate, sapos enfeitiçados que contém uma figurinha com um bruxo famoso e seus feitos.

Para exemplificar o que foi mencionado, segue o trecho de "Harry Potter e a Pedra Filosofal":

Alvo Dumbledore, atualmente diretor de Hogwarts. Considerado por muitos o maior bruxo dos tempos modernos. Dumbledore é particularmente famoso por ter derrotado Grindelwald, bruxo das Trevas, em 1945, por ter descoberto os doze usos do sangue de dragão e por desenvolver um trabalho em alquimia em parceria com Nicolau Flamel. O Professor Dumbledore gosta de música de câmara e boliche. (Rowling, 2000, p.78).

O verdadeiro intuito da alquimia também foi explorado nas páginas do livro, mas de forma mais simplificada, dando uma importância a pedra filosofal e seu descobridor, Nicolau Flamel:

O antigo estudo da alquimia preocupava-se com a produção da Pedra Filosofal, uma substância lendária com poderes fantásticos. A pedra pode transformar qualquer metal em ouro puro. Produz também o Elixir da Vida, que torna quem o bebe imortal. (Rowling, 2000, p.160).

Em outro volume da saga, no livro $O$ prisioneiro de Azkaban temos a interdisciplinaridade sendo abordado dentro das páginas do livro, o que implica seu uso pedagógico não apenas para professores de química, como também professores de outras áreas da ciência. Isso denota ainda mais a importância do uso de livros paradidáticos como ferramentas auxiliadoras no aprendizado. Ora, os alunos, quando estão estudando química muitas vezes se acometem no erro de achar que não existe nada mais envolvido naquele aprendizado, isso está relacionado a pedagogia tradicional, na qual o professor se sente responsável apenas por "passar seu conteúdo", deixando de lado na maioria das vezes o caráter interdisciplinar da Ciência como um todo, em que todas as áreas se completam.

A interdisciplinaridade está nas entrelinhas do livro O prisioneiro de Azkaban, como este artigo não aborda este título da saga, deixemos este assunto um pouco de lado; por outro lado, um fato curioso no terceiro título da saga é a perseguição que as bruxas sofreram no período da Santa Inquisição, que buscava erradicar aqueles que não seguiam os dogmas pregados pela Igreja. Este importante fato que levou a morte de muitas mulheres, que eram consideradas bruxas, por terem conhecimento é retratado no livro, e isso evidencia que a coletânea possui uma forte interdisciplinaridade que poderá ser utilizada em vários campos do conhecimento humano como ferramenta pedagógica facilitadora da aprendizagem.

\section{Pedra Filosofal Real: da Alquimia para a Química Moderna}

A contribuição que a alquimia teve para com a química quanto ciência moderna estão por toda parte; poderíamos citar, por exemplo, o banho maria que é uma técnica desenvolvida por uma alquimista: Maria, a Judia. Algumas vidrarias e materiais de laboratórios, que hoje fazem parte do acervo de um laboratório moderno, fizera parte também dos laboratórios alquímicos, como é o caso do almofariz e pistilo, balanças, destiladores; vidrarias como balões de fundo chato, bem como os reagentes utilizados, porém, com a ressalva de que em muitos casos os reagentes não eram puros e eram encontrados na forma de mistura, além conhecidos por outro nome. Água Régia, por exemplo, conhecida por corroer os metais, era o que hoje conhecemos por ácido clorídrico $(\mathrm{HCl})$ misturado com ácido cítrico $\left(\mathrm{HNO}_{3}\right)$, esta mistura corrosiva era capaz até mesmo de corroer ouro. 
A contribuição mais valorosa da alquimia para a química, podemos citar a transmutação decorrente da pedra filosofal, a tentativa de transformar metal "comum" em ouro. A ideia principal, de criar a pedra filosofal, foi deixada de lado e deu-se maior atenção em transformar um metal qualquer em ouro, ou melhor dizendo, transmutar um átomo em outro.

As reações químicas são, geralmente, transformações ocorridas com a matéria de forma que essas mudanças são observadas na composição química de uma ou mais substâncias envolvidas, resultando em produtos. As reações químicas são perceptíveis a olho nu, pois mudam de cor, exalam cheiros, esquentam em reações exotérmicas, esfriam em reações endotérmicas. Mas também existem as reações de transmutações, que não fogem a regra já citada neste parágrafo e embora sejam reações atômicas, também emitem ao mundo macroscópico evidências de que estão ocorrendo, como a emissão de luz (no espectro visível ou não) e altas emissões de energia.

Quando um átomo sofre transformação em seu núcleo origina-se um novo elemento, isso se chama transmutação, e pode ser natural ou artificial. Partindo da ideia alquímica de transmutação, os cientistas da modernidade conseguiram aquilo que os alquimistas sempre buscaram, mas não da forma como esperava-se; a transmutação é um marco na História da Ciência.

Transmutação é um assunto a ser abordado em Atomística no ensino médio, quando o discente está estudando sobre modelos atômicos, haja vista que é necessário entender do que a matéria é formada para então compreender como ocorrem as transformações da matéria. Muitos docentes optam por não abordarem o assunto de transmutação, o que se torna um erro pois cria na mente do aluno que as reações químicas só podem ocorrer de forma a serem observadas no campo macroscópico de observação, sendo que também podem ocorrer emissões de sinais invisíveis (cumprimento de ondas fora do espectro visível).

A abordagem da Transmutação é de suma importância para a formação científica do aluno e principalmente para sua formação social, pois o professor pode abordar o assunto de Transmutação com o intuito de provocar reflexões de como a ciência pode ser utilizada de maneira tão devastadora e de forma imprudente, visto que a Transmutação artificial, aquela que é provocada por bombardeamento de núcleo atômico fazendo o uso de partículas subatômicas (prótons, nêutrons, pósitrons, múons, mésons), ocasiona a fissão nuclear e a emissão gigantesca de energia; essa energia pode ser armazenada para ser utilizada como arma de destruição em larga escala (Bombas Nucleares). Porém, quando utilizada de maneira correta pode abastecer uma cidade grande por muitos meses, suprindo a demanda de energia elétrica.

\section{Considerações Finais}

Embora a saga de livros Harry Potter seja uma saga com mais de vinte anos desde a publicação de seu primeiro volume (1997) no Brasil sua primeira publicação ocorreu em 2000 e desde então a saga teve várias reedições, traduzidas para muitas línguas, com adaptações cinematográficas de boa qualidade, o conteúdo no interior de suas páginas com potencial pedagógico passa, muitas vezes, despercebido.

Levando em consideração a linguagem que o livro traz, uma linguagem aceita pelos jovens, moderna e atual, o potencial pedagógico se torna eficaz; pois irá familiarizar o aluno com o hábito de leitura, torna o professor mais próximo de seus alunos devido a utilização de linguagens próprias transmitidas pelo livro, além da criação de laços afetivos devido aos gostos literários a serem compartilhados.

Além de facilitar o entendimento do conteúdo a ser explorado, tomando as passagens do texto como uma forma fantasiosa exemplificada. Logicamente, cabe ao professor proporcionar a seus alunos discursões sociais acerca do conteúdo. Sempre buscando tornar a interdisciplinaridade um conceito a fazer parte de sua metodologia. Lembrando que também é possível fazer comparações com o mundo real sempre que possível.

Os benefícios do uso da literatura como uma ferramenta pedagógica no ensino de ciências são diversos, mas dentre os quais podemos citar: incentivo à leitura, exercitar o senso crítico e filosófico dos alunos, mostra-lhes como se dá o avanço científico, proporcionar que o aluno estimule a sua imaginação. 
O uso de livros paradidáticos como uma ferramenta didática não se dá apenas para livros de fantasia, outros títulos, como os mencionados neste artigo, podem ser utilizados por professores. Sendo utilizados como uma ferramenta facilitadora que os ajude a passar conhecimento de forma dinâmica e divertida a seus alunos. O que abre espaço para saber quais capacidades cognitivas serão trabalhadas quando se muda o gênero literário como ferramenta didática.

Não apenas livros podem ser utilizados como ferramentas pedagógicas, é preciso levar em consideração uma série de fatores que, muitas vezes, podem passar despercebidos quanto a seus potenciais didáticos; tais como histórias em quadrinhos, graphic novels, séries que sempre buscam relatar problemas sociais, descobertas e assuntos científicos que podem instigar a criatividade e autonomia do aluno em uma atividade interdisciplinar de avanço cognitivo.

\section{Referências}

Aragão, M. J. (2008). História da Química. Interciência.

Asimov, I. Y. (2019) Fundação. Tradução de Fábio Fernandes. Aleph.

Barbosa, A. M. Tópicos Utópicos. (1998). C/Arte.

Carvalho, R. S.; \& Silva, A. C. S. Estórias do Harry Potter: um catalisador para o estudo da alquimia. Revista ponto de vista, 5(1), 113-125. https://periodicos.ufv.br/RPV/article/view/9726.

Descartes, R. (1984) Paixões da Alma. Abril Cultural (coleção Os Pensadores).

Enzensberger, H. M. (1997) O Diabo dos números. tradução de Sergio Tellaroli. Cia das Letras.

Farias, C. A. (2006) Alfabetos da alma: histórias da tradição na escola. Sulina.

Filgueiras, C. A. L. A história da ciência e o objeto de seu estudo: confronto entre a ciência periférica, a ciência central e a ciência marginal. Química Nova. 24(5), 709-712. http://quimicanova.sbq.org.br/default.asp?ed=23.

Platão. (1978) Fedon. Abril Cultural. (coleção Os Pensadores).

Programa nacional do livro e material didático. (2018). https://www.fnde.gov.br/pnld-2018/.

Rhoden, J., \& Zancan, S. (2020). A perspectiva da abordagem qualitativa narrativa de cunho sociocultural: possibilidade metodológica na pesquisa em educação. Educação (UFSM), 45, e61/ 1-22

Rowling, J. K. (2000) Harry Potter e a pedra filosofal. tradução de Lia Wyler. Rocco.

Sartre, J. P. (1987) A Imaginação. Os Pensadores. Nova Cultural.

Smolka, A. L. (2009). Comentários. In Vigotski, L. S. Imaginação e criação na infância: ensaio psicológico: livro para professores. Apresentação e comentários Ana Luiza Smolka; Tradução de Zóia Prestes. Ática.

Verne, J. (2014) Vinte mil léguas submarinas. tradução de Julia da Rosa Simões. Penguin Classics Companhia das Letras.

Vygotsky, L. S. Teoria e método em psicologia. (1996). Martins Fontes.

Vygotsky, L. S. A construção do pensamento e da linguagem. (2001a), Martins Fontes. 